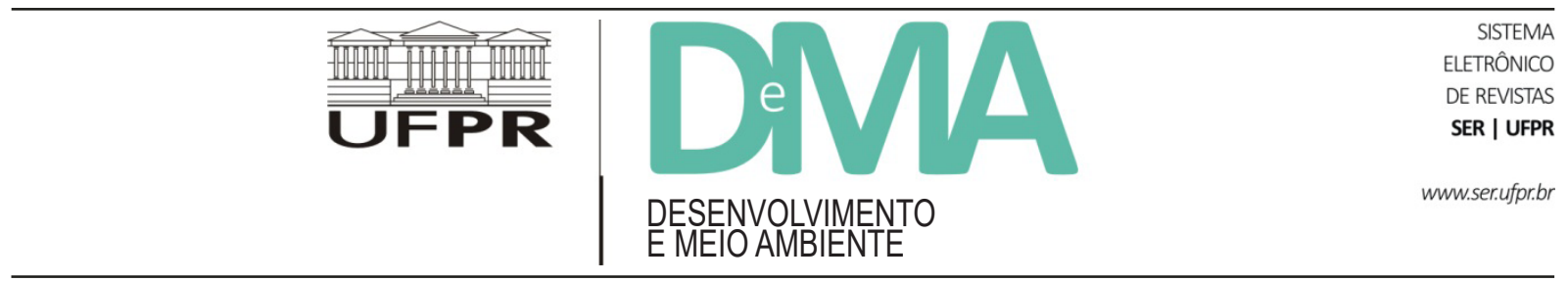

\title{
Masificación de la agroecología: impulsores clave y casos emblemáticos ${ }^{1}$
}

\section{Ampliação da agroecologia: principais impulsores e casos emblemáticos}

\section{Bringing agroecology to scale: key drivers and emblematic cases}

\author{
Mateo MIER y TERÁN Giménez Cacho ${ }^{1,6^{*}}$, Omar Felipe GIRALDO ${ }^{2}$, Miriam ALDAROSO $^{1,6}$, Helda \\ MORALES ${ }^{1}$, Bruce G. FERGUSON ${ }^{1}$, Peter ROSSET ${ }^{1,3,4,5}$, Ashlesha KHADSE ${ }^{1}$, Carmen CAMPOS ${ }^{1}$ \\ ${ }^{1}$ El Colégio de la Frontera Sur (ECOSUR), San Cristóbal de Las Casas, Chiapas, México. \\ ${ }^{2}$ Universidad Nacional Autónoma de México (UNAM), Escuela Nacional de Estudios Superiores (ENES), Mérida, Yucatán, México. \\ ${ }^{3}$ Profesor BPV-FUNCAP del Programa de Pós-Graduação em Sociologia (PPGS), Universidade Estadual do Ceará (UECE), Fortaleza, CE, Brasil; \\ ${ }^{4}$ Profesor Colaborador del Programa de Pós-Graduação em Desenvolvimento Territorial na América Latina e Caribe (TerritoriAL), Universidade \\ Paulista (UNESP), São Paulo, SP, Brasil. \\ ${ }^{5}$ Profesor visitante, Social Research Institute (CUSRI), Chulalongkorn University (Chula), Bangkok, Tailandia. \\ ${ }^{6}$ Cátedras Conacyt-Ecosur - \#cienciabajoprotesta \\ *E-mail de contacto: mmieryteran@ecosur.mx
}

Artículo recibido en 15 de junio de 2021, publicado en 30 de noviembre de 2021.

RESUMEN: La agroecología ha ganado impulso como movimiento trasformador en muchos países y ha crecido más allá de experiencias locales aisladas. La cantidad de familias y comunidades que procesan distribuyen y consumen alimentos que se produce de forma agroecológica va en aumento. Para entender el proceso no lineal y multidimensional que ha facilitado la expansión de la agroecología, analizamos en este texto el Movimiento de Campesino a Campesino centroamericano; el movimiento nacional agroecológico de campesinos en Cuba; el boom del café orgánico en Chiapas, México; la expansión de la Agricultura Natural de Presupuesto Cero

\footnotetext{
${ }^{1}$ Este artículo fue publicado originalmente en inglés en: Mier y Terán G. C., M.; Giraldo, O. F.; Aldaroso, M.; Morales, H.; Ferguson, B. G.; Rosset, P.; Khadse, A.; Campos, C. Bringing agroecology to scale: key drivers and emblematic cases. Agroecology and Sustainable Food Systems, 42(6), 637-665, 2018.
} 
en Karnataka, India, y la brasileña Ecovida. Hemos identificado ocho impulsores clave que han llevado a la agroecología a mayor escala: 1) el reconocimiento de una crisis que motiva la búsqueda de alternativas; 2) la organización social; 3) los procesos de aprendizaje constructivista; 4) las prácticas agroecológicas efectivas; 5) los discursos movilizadores; 6) los aliados externos; 7) los mercados favorables, y 8) las oportunidades y marcos políticos favorables. Mostramos que la organización y el tejido social son los medios principales que impulsan el avance de la agroecología; y que se necesita una comprensión más detallada de cómo estas múltiples dimensiones interactúan, se refuerzan y generan una retroalimentación positiva entre sí para hacer posible la expansión territorial de la agroecología.

Palabras clave: transformación del sistema agroalimentario; campesino a campesino; ampliación de la agroecología; escalamiento horizontal; territorialización de la agroecología.

RESUMO: A agroecologia como um movimento transformador tem ganhado ímpeto em muitos países do mundo inteiro. Em vários casos, a implementação de práticas agroecológicas tem crescido para além das experiências locais isoladas. O número de famílias e comunidades que processam, distribuem e consomem alimentos produzidos agroecológicamente está a aumentar. A fim de compreender o processo não linear e multidimensional que tem facilitado e impulsionado a expansão da agroecologia, revemos e analisamos casos emblemáticos que incluem o Movimento Camponês a Camponês na América Central, o movimento camponês agroecológico nacional em Cuba, o boom do café orgânico em Chiapas, México, a expansão da Agricultura Natural Orçamento Zero em Karnataka, Índia, e a Ecovida, uma rede de mercados agroecológicos de venta direta ao consumidor no Brasil. Com base em nosso análise, identificamos 8 fatores-chave no processo de levar a agroecologia à maior escala: 1) reconhecimento de uma crise que motiva a procura de alternativas; 2) organização social; 3) processos de aprendizagem construtivistas; 4) práticas agroecológicas efetivas; 5) discursos mobilizadores; 6) aliados externos; 7) mercados favoráveis, e 8) oportunidades políticas e políticas favoráveis. Esta análise inicial mostra que a organização e o tecido social são os meios de crescimento em que a agroecologia avança, com a ajuda dos outros motores. É necessário um entendimento mais detalhado sobre como estas múltiplas dimensões interagem, reforçam, e geram um feedback positivo entre si para tornar possível a expansão territorial da agroecologia.

Palavras-chave: transformação do sistema agroalimentar; camponês a camponês; ampliação da agroecologia; escalamento horizontal; territorialização da agroecologia.

ABSTRACT: Agroecology as a transformative movement has gained momentum in many countries worldwide. In several cases, the implementation of agroecological practices has grown beyond isolated, local experiences to be employed by ever-greater numbers of families and communities over ever-larger territories and to engage more people in the processing, distribution, and consumption of agroecologically produced food. To understand the nonlinear, multidimensional processes that have enabled and impelled the bringing to scale of agroecology, we review and analyze emblematic cases that include the farmer-to-farmer movement in Central America; the national peasant agroecology movement in Cuba; the organic coffee boom in Chiapas, Mexico; the spread of Zero Budget Natural Farming in Karnataka, India; and the agroecological farmer-consumer marketing network "Rede Ecovida," in Brazil. Based on our analysis, we identify eight key drivers of the process of taking agroecology to scale: 1) recognition of a crisis that motivates the search for alternatives; 2) social organization; 3 ) constructivist learning processes; 4) effective agroecological practices; 5) mobilizing discourses; 6) external allies; 7) favorable markets, and 8) favorable policies. This initial analysis shows that organization and social fabric are the growth media on which agroecology advances, with the help of the other drivers. A more detailed understanding is needed on how these multiple dimensions interact with, reinforce, and generate positive feedback with each other to make agroecology's territorial expansion possible.

Keywords: agri-food system transformation; farmer-to-farmer; massification of agroecology; scaling out; territorialization of agroecology. 


\section{Introducción}

La ciencia y la práctica de la agroecología nos ofrecen los fundamentos para una transformación radical de los sistemas alimentarios (Wezel, et al. 2009; Gliessman, 2015); se trata de una propuesta de un creciente movimiento de liberación que aspira a incrementar el poder y el control de los agricultores sobre su propia producción, a fomentar procesos sociales para la difusión de las prácticas agroecológicas, y la expansión del acceso a alimentos elaborados con métodos saludables que respeten el ambiente (Altieri \& Toledo, 2011; Rosset \& Martínez-Torrres, 2012; Martínez-Torres \& Rosset, 2014; Rosset \& Altieri, 2018). Sin embargo, a pesar de su reconocimiento en los últimos años (IAASTD, 2008; IPES-Food, 2016), son pocos los casos de éxito de la agroecología en los que participan miles de familias en una región específica y que hayan sido documentados a detalle.

Es una escasez que se entiende por la masiva cantidad de políticas, instituciones y corporaciones que se dedican a crear y mantener un ambiente económico y político ideal para el modelo de la agricultura industrial (Van Der Ploeg, 2008; McMichael, 2013). Pero, pese a tanta oposición, el éxito de la agroecología merece investigarse. La agricultura industrial ha contaminado la tierra, el agua y el aire, ha erosionado los suelos, dañado la biodiversidad, incrementado las enfermedades, provocado el endeudamiento de los agricultores, y ha contribuido al abandono del campo (Carrol et al., 1990; Lappé et al., 1998). Además, ha fracasado en su promesa de eliminar el hambre (Patel, 2007; De Shutter, 2010); ello sin contar que, durante el régimen neoliberal, la élite económica ha usurpado los recursos (Borras et al., 2012). Por tales razones, es esencial entender dónde y cómo es que la agroecología ha superado esos obstáculos.

La práctica agroecológica ha devuelto su importancia al conocimiento campesino, y se le ha entendido no como un conjunto de recetas, sino como una serie de principios aplicados de acuerdo a la realidad particular de cada agricultor (Atieri, 1995, 2000; Gliessman, 2015; Rosset \& Altieri, 2018). Una finca totalmente agroecológica se sustenta en la biodiversidad cultivada y no cultivada, incluyendo la integración de cultivos, árboles y ganadería a nivel del terreno y del paisaje (Nicholls et al., 2001; Altieri \& Rogé, 2009; Perfecto et al., 2009; Gliessman, 2015). Ahora bien, aunque las estrategias de sustitución de insumos -por ejemplo, el remplazo de pesticidas químicos por microbianos o el uso de compostaje comercial en lugar de fertilizantes sintéticos- a veces se les considera técnicas agroecológicas, e incluso ecológica y socialmente más aceptables que su contraparte industrial, en realidad pueden mantener una dependencia en relación con la compra de insumos por parte de los agricultores, lo que llevar a consecuencias ecológicas no deseadas (Rosset \& Altieri, 1997; Gliessman, 2015; Vandermeer \& Perfecto, 2017). La agroecología, en cambio, busca reducir esa dependencia a mediano y largo plazo, puesto que su objetivo es contribuir a la autonomía de las comunidades y familias productoras de alimentos (Rosset \& MartínezTorres, 2012); y en su desarrollo máximo, propone la organización y conexión de consumidores y productores para conformar sistemas alimentarios justos, con responsabilidad ambiental, además de movimientos más amplios por la justicia social, 
política y económica (Gliessman, 2011; Rosset \& Martínez-Torres, 2012).

La expansión de la agroecología se sitúa en la urgente necesidad de transformar los sistemas alimentarios (Altieri \& Nicholls, 2008; De Schutter, 2011; 2012; Pamentier, 2014; Rosset \& Altieri, 2018); una "expansión", "masificación", "amplificación" o "territorialización" que aquí definimos como el proceso por el cual un número cada vez mayor de familias la practican en territorios cada vez más extensos, involucrando a más personas en el procesamiento, distribución y consumo de alimentos agroecológicos ; aunque para que esto suceda, debe expandirse y consolidarse a lo largo de varios ejes (IIRR, 2000; Gonsalves, 2001; Ranaboldo \& Venegas, 2007; Altieri \& Nicholls, 2012; Parmentier, 2014; Brescia, 2017). Además, el escalamiento suele combinar procesos verticales y horizontales (IIRR, 2000; Rosset \& Altieri, 2018). Los primeros se conciben como institucionales por naturaleza, mientras que los segundos están frecuentemente asociados a movimientos populares y se distinguen por buscar la expansión geográfica y la inclusión social de más personas y comunidades (IIRR, 2000; Rosset \& Martínez-Torres, 2012). El escalamiento de la agroecología significa entonces que una mayor cantidad de población rural y urbana pueda producir alimentos saludables, nutritivos, diversos, ambientalmente compatibles y culturalmente apropiados, y/o acceder a ellos (Rosset, 2014; Rosset \& Altieri, 2018).

Este estudio contribuye a la comprensión teórica de los procesos de escalamiento de la agroecología analizando cinco casos emblemáticos de su masificación en el mundo. Con ese fin identificamos para cada uno los impulsores clave que han facilitado su crecimiento más allá de las experiencias locales aisladas. Los casos fueron seleccionados con base en su alcance territorial, en la cantidad de familias involucradas, en la magnitud y calidad en su documentación, y en nuestra experiencia directa con ellos. No pretendemos explorarlos exhaustivamente. Lo que haremos será identificar los elementos comunes que permitan entender cuáles son los factores necesarios para escalar la agroecología. Emprendemos también un primer intento de elucidar las relaciones complejas entre esos factores a fin de formular y evaluar estrategias para el avance de las transformaciones agroecológicas. Cabe decir que los trabajos de Gonsalves (2001) y Parmentier (2014) ya han determinado elementos clave de dicho escalamiento. El primero proporcionando orientación para organizaciones no gubernamentales (ONG) y agencias de desarrollo que promueven la agroecología, y el segundo al formular y recomendar políticas públicas para los gobiernos. En este trabajo argumentamos que, aunque las ONG, los gobiernos y otros sectores pueden contribuir con recursos esenciales y ayudar a crear ambientes apropiados, los procesos de escalamiento más exitosos se singularizan por sustentarse en movimientos sociales amplios e inclusivos (Rosset et al., 2011; Rosset, 2014; Khadse et al., 2017; Rosset \& Altieri, 2018).

\section{Cinco casos emblemáticos de la masificación de la agroagricultura}

\subsection{Caso uno: Movimiento Campesino a Campesino en Mesoamérica}

El Movimiento Campesino a Campesino $(\mathrm{CaC})$ nació en los inicios de la década de 1970 en Chimaltenango, Guatemala, como una iniciativa 
de campesinos mayas kaqchikeles, y con el apoyo de OXFAM y Vecinos Mundiales (Holt-Giménez, 2006). Los campesinos indígenas usaron su tradición de la ayuda mutua; las prácticas pedagógicas populares horizontales congruentes con la praxis freiriana de "acción- reflexión-acción" (Freire, 1970); la educación popular de Latinoamérica; la teología de la liberación, y la cultura indígena a la que pertenecían (Holt-Giménez, 2006). Realizaron visitas recíprocas a las fincas, siembras demostrativas y experimentación en pequeña escala, para aprender de forma conjunta las técnicas para la conservación del suelo y el agua; y prácticas como abonos verdes, barreras de contorno vivas y muertas, diversificación de cultivos y agroecología intensiva. Estas mejoras agrícolas, junto con la organización de la cooperativa Kato-Ki, aumentaron la producción y los ingresos. Los campesinos empezaron a liberarse del trabajo en plantaciones privadas e incluso tuvieron la capacidad para comprar y redistribuir tierra de fincas cafetaleras cercanas. No obstante, durante la brutal represión de los años ochenta, los latifundistas recurrieron a los militares para que destruyeran la cooperativa maya Kato-Ki y muchas de las fincas del CaC.

Con el apoyo de las ONG, los campesinos que tuvieron que huir hallaron trabajo con proyectos de base en México, Honduras y Nicaragua, donde continuaron desarrollando su experiencia con agricultura sustentable y sus habilidades organizativas (Holt-Giménez 2006). Dada la diáspora campesina, la metodología $\mathrm{CaC}$ se expandió entre múltiples organizaciones en la región. Entre los proyectos más exitosos se encuentran el Centro de Desarrollo Integral Campesino de la Mixteca (CEDICAM) ${ }^{2}$, en Oaxaca, y el Grupo Vicente Guerrero ${ }^{3}$, en Tlaxcala (Boege \& Carranza, 2009). Estos grupos adaptaron la metodología de Guatemala a su contexto social y desarrollaron un amplio repertorio metodológico y técnico. En 1986 campesinos de Vicente Guerrero, siempre con apoyo de ONG y un limitado respaldo del gobierno sandinista, compartieron su metodología con la Unión Nacional de Agricultores y Ganaderos de Nicaragua (UNAG). Esta fue una de las organizaciones creadoras de La Vía Campesina (LVC) ${ }^{4}$, un movimiento campesino transnacional. En Nicaragua, el CaC creció como un amplio movimiento de base para el cambio social asentado en la agricultura sustentable campesina -la agroecología-, incluyendo a 30,000 familias campesinas a lo largo de todo el país. Este "movimiento de resistencia", como fue definido por sus participantes, apoyó a los campesinos contra las amenazas de la agricultura industrial promoviendo la agroecología social, cultural, económica y ambientalmente sustentable (Holt-Giménez, 2006).

\subsection{Caso dos: Asociación Nacional de Agricultores Pequeños y la revolución agroecológica en Cuba}

Cuba fue el país latinoamericano que adoptó el paquete tecnológico de la revolución verde con mayor intensidad (Machín Sosa et al., 2010; 2013;

\footnotetext{
2 https://www.facebook.com/Cedicam-195930244166548/

3 https://www.facebook.com/gvgTlaxcala/

4 La UNAG se retiró posteriormente de LVC.
} 
Rosset et al., 2011). Sin embargo, la agroecología fue clave para ayudar a la sobrevivencia de los cubanos durante la crisis provocada por el colapso del bloque socialista entre 1989 y 1990, y el posterior recrudecimiento del embargo comercial de los Estados Unidos de América (EUA). Los campesinos cubanos promovieron la producción alimentaria sin insumos escasos y caros, sustituyendo primero los insumos importados no accesibles y luego transformando sus fincas en sistemas agroecológicos integrados con cada vez mayor diversidad en la producción. Las prácticas claves incluyeron la conservación del suelo, rotación de cultivos, abonos verdes y composta, policultivos y agroforestería, control biológico de plagas, integración de ganado a la producción agrícola, y diversificación. La rápida transformación agrícola cubana fue posible no porque existieran alternativas apropiadas disponibles, sino porque el proceso social y metodológico $\mathrm{CaC}$ fue implementado por la Asociación Nacional de Agricultores Pequeños (ANAP), organización miembro de LVC, el cual, aprendido de Mesoamérica, se adaptó y utilizó para construir un movimiento agroecológico de base.

Entre 1997 y 2010, un tercio de las familias campesinas de Cuba participaron en el Movimiento Campesino a Campesino promovido por la ANAP (Machín Sosa et al., 2010, 2013; Rosset et al., 2011; Val, 2012). Desde entonces este movimiento ha crecido hasta incluir 200,000 familias campesinas, aproximadamente la mitad del campesinado cubano. La rápida expansión de la agroecología se atribuye parcialmente a la metodología basada en un proceso social y a las dinámicas de organización de base que el movimiento impulsó. El cambio a prácticas agroecológicas contribuyó significativamente al crecimiento relativo y absoluto de la producción del sector campesino, y aportó otros beneficios, incluyendo resiliencia ante el cambio climático (Rosset et al., 2011; Funes \& Vázquez, 2016).

\subsection{Caso tres: auge del café orgánico en Chiapas, México}

Los campesinos indígenas en Chiapas, México, quienes abastecen el mercado mundial con café orgánico, ofrecen otro ejemplo ilustrativo de la expansión agroecológica (Martínez-Torres, 2006). El proceso ha estado influido, impulsado y apoyado por la teología de la liberación de la Iglesia católica y su opción preferencial por los pobres (HernándezCastillo, 2010). La recuperación de saberes de la cosmovisión maya, la diversificación de cultivos, el manejo ecológico del suelo, el fortalecimiento de la identidad indígena, la organización en cooperativas, y el vínculo con el comercio justo mediante el sello Max Havelaar, han sido elementos centrales en esta experiencia (Renard, 2003; Martínez-Torres, 2006). Un aspecto muy importante que explica la transición del café cultivado con el enfoque de la agronomía convencional al café orgánico, fue la liquidación del Instituto Mexicano de Café (IMECAFE) en 1989 -órgano que había controlado la mitad de las exportaciones de café en el país-, lo cual confluyó con la caída de los precios internacionales, y la pérdida de rendimientos y rentabilidad como resultado de las tecnologías de la revolución verde.

Esa combinación de eventos produjo una crisis para las familias cafeticultoras, pero también una oportunidad (Martínez-Torres, 2006). Como respuesta a la crisis, inició un proceso organizado para la comercialización del café orgánico bajo el modelo de producción orgánica y comercio justo. Ese proceso, que garantizó un mejor 
precio para las familias productoras (MartínezTorres, 2006), fue posible por la participación de muchos actores. Entre ellos las cooperativas respaldadas por la teología de la liberación, los grupos políticos de izquierda presentes en la región desde 1970, las cooperativas que IMECAFE había apoyado durante tres décadas, y algunas otras que habían sido constituidas autogestivamente (Nigh, 2002; Martínez-Torres, 2006). También fueron importantes los servicios de infraestructura creados durante el periodo de IMECAFE y los vínculos con la Unión de Comunidades Indígenas de la Región del Itsmo (UCIRI) en Oaxaca, que ya había establecido un esquema para la comercialización de café orgánico. Las cooperativas aprendieron de los exitosos ejemplos agroecológicos y las prácticas agroforestales desarrolladas en la Finca Irlanda y por los promotores agroecológicos de Guatemala, quienes habían sido desplazados por la guerra civil en su país. Adicionalmente hubo mucho intercambio entre los campesinos indígenas (Martínez-Torres, 2006). Este movimiento, vinculado a la exportación y a los sellos de certificación orgánica (Martínez-Torres, 2006), en la actualidad agrupa aproximadamente a 31,000 familias campesinas, en su mayoría indígenas, que trabajan en una superficie que abarca 72,000 hectáreas, obteniendo las mismas cosechas de los productores convencionales, pero con un mejor margen de ganancia (Martínez-Torres, 2006).

\subsection{Caso cuatro: la Agricultura Natural de Presupuesto Cero en India}

La Agricultura Natural de Presupuesto Cero (ZBNF, por sus siglas en inglés) es un conjunto de prácticas tradicionales y agroecológicas que el agrónomo Subhash Palekar reunió, y que se ha convertido en la base de un movimiento campesino que se ha extendido a varios estados de la India (Khadse et al., 2017). El movimiento ha alcanzado amplio éxito, especialmente en Karnataka, estado del sur de India, donde encontró tierra fértil en el ambiente organizativo de la Asociación de Campesinos del Estado Karnataka (KRRS, por sus siglas en inglés), miembro de LVC. Se estima que solo en Karnataka participan 100,000 familias campesinas; mientras que a nivel nacional pueden ser millones, según los líderes de la ZBNF. Este grado de participación se logró sin el involucramiento de alguna organización formal, sin personal asalariado e incluso sin tener una cuenta bancaria. El movimiento se beneficia del espíritu voluntario que prevalece entre los campesinos participantes. Parte de la capacidad de atracción de campesinos proviene del carisma de Palekar, de la poderosa mezcla de cosmología hindú, y de la resistencia en contra de las corporaciones y la revolución verde (Bhattacharya, 2017; Khadse et al., 2017).

A nivel local el movimiento se desarrolla informalmente con una dinámica autoorganizada. La mayoría de los campesinos que participan en la ZBNF están conectados entre sí espontáneamente llevando a cabo actividades de intercambio al estilo de $\mathrm{CaC}$, y los líderes tienden a surgir naturalmente del movimiento de base. A nivel del estado, las principales actividades son talleres de formación dirigidos por Palekar, los cuales pueden durar hasta cinco días, con actividades durante ocho horas consecutivas, en las que participan entre 300 y 5,000 campesinos. Las redes entre campesinos, las visitas cruzadas a plantaciones vecinas y la relación entre 
campesinos educadores se desarrollan entre los contactos establecidos en los talleres de formación (Khadse et al., 2017).

Quienes respondieron a una evaluación señalan que la ZBNF es efectiva para los agricultores en términos agronómicos, sociales y económicos (Khadse et al., 2017). La mayoría reportó que el uso continuo de sus prácticas, como biofertilizantes, control biológico de pestes, barreras de contorno, policultivos y abono, mejora las cosechas, la conservación del suelo, la diversidad de semillas, la calidad de producción, la autonomía alimentaria del hogar, el ingreso y la salud. Las motivaciones para unirse a este movimiento que generalmente citan los agricultores incluyen la salud de sus familias, la autosuficiencia alimentaria y la reducción del costo de producción. La mayoría reduce sus gastos de producción y por tanto la necesidad de crédito, uno de los mayores problemas que afecta a los agricultores y campesinos en India.

\subsection{Caso cinco: Red Ecovida en el sur de Brasil}

La Red Ecovida fue creada formalmente en 1998; sin embargo, se le puede rastrear ya entre los años setenta y ochenta, cuando movimientos sociales paralelos confrontaron tanto la concentración de tierra, como los daños ambientales y sociales provocados por la agricultura moderna dependiente de agroquímicos (Charão \& Oliveira, 2016). La combinación de estas amenazas, y las organizaciones conformadas para luchar en su contra, crearon las condiciones adecuadas para el surgimiento de diversas iniciativas agrícolas alternativas, que posteriormente fueron denominadas "agroecología". Estos esfuerzos estuvieron conectados con la Red de Tecnología Alternativa del Sur, la cual se encontraba ligada al Proyecto Red de Tecnología Alternativa (Rede PTA, por sus siglas en portugués). Adicionalmente se formaron nexos con procesos promovidos por la Pastoral de la Tierra de la Iglesia católica, sustentada en la teología de la liberación y con otras organizaciones locales en búsqueda de alternativas (Charão \& Oliveira, 2016). Actualmente, Ecovida une a ONG, grupos y cooperativas de consumidores, cooperativas y organizaciones de campesinos y agricultores que practican la agroecología. Ecovida tiene una estructura descentralizada en 150 municipalidades de los tres estados del sur de Brasil: Rio Grande do Sul, Santa Catarina y Paraná. El movimiento se ha expandido a 29 organizaciones de agricultores, 2,700 agricultores familiares, 10 cooperativas de consumidores, 25 asociaciones y 30 agroindustrias ubicadas en 18 municipalidades, con más de 180 mercados campesinos (Ecovida, 2017).

Aunque Ecovida se centra en mercados (Hebinck et al., 2014), las actividades de sus miembros están arraigadas en prácticas agroecológicas. Sus miembros siguen los principios de horizontalidad, solidaridad, justicia y cuidado de la naturaleza, lo cual penetra la lógica organizativa de sus actividades, y les permite ir más allá de la mercantilización o de producir solo por obtener una ganancia. La certificación participativa de Ecovida la iniciaron al final de 1990, como respuesta al intento gubernamental de regular la producción orgánica (Perez-Cassarino, 2012). El programa de certificación es un ejemplo del enfoque pedagógico horizontal de Ecovida, cuya meta es el aprendizaje transformador (Radomsky, 2010). Los miembros de Ecovida siguen una comprensión sistémica de la 
agroecología y promueven la solidaridad económica entre productores y consumidores (Perez-Cassarino, 2012). La estructura de esta economía permite configurar diferentes tipos de mercados que incluyen la venta ambulante de puerta en puerta, los mercados campesinos, la venta a cafeterías comunales, a grupos de consumidores y restaurantes, así como la comercialización entre mercados en el circuito de los tres estados involucrados (Perez-Cassarino, 2012; Charão \& Oliveira, 2016).

\section{Impulsores claves en la masificación de la agroecología}

En el análisis de estos cinco casos están presentes ocho factores interrelacionados que tienen efectos solos o en concomitancia para promover y mantener la masificación de la agroecología $\left.{ }^{5}: 1\right)$ crisis que impulsan la búsqueda de alternativas; 2) organizaciones sociales; 3 ) procesos de enseñanza-aprendizaje constructivista; 4) prácticas agroecológicas efectivas; 5) discurso movilizador; 6) alianzas externas; 7) mercados favorables; y 8) oportunidades políticas favorables. $\mathrm{Al}$ inicio de un proceso en particular, uno o varios de esos factores pueden conducir al escalamiento. Sin embargo, la retroalimentación y sinergia positivas surgen entre los impulsores a medida que avanza su expansión, activando y potenciando así a otros impulsores. Proponemos como hipótesis de trabajo que un escalamiento agroecológico fuertemente articulado y resiliente resulta de la integración de varios factores. Los ochos factores referidos muestran haber sido claves para la territorialización de la agroecología en la mayoría o en los cinco casos, pero indudablemente más factores contribuyeron en algunos otros. Además, el acceso a la tierra para las familias de agricultores es una necesaria condición previa para la agroecología y su crecimiento. A continuación describimos cómo estos factores determinan el escalamiento agroecológico.

\subsection{Impulsor uno: crisis que fomentan la búsqueda de alternativas}

El primer elemento que hemos identificado es el de las crisis. En todos los casos analizados la identificación de una crisis fue una condición que motivó el cambio, aunque insuficiente por sí misma. A pesar de que la crisis se expresó de diversas maneras en cada una de las experiencias estudiadas, fue totalmente necesario que mediaran múltiples factores para que se detonara el proceso de transformación. Si bien la crisis ha sido una condición que sirve de clima propicio para buscar alternativas distintas al modelo agroindustrial, requiere ineludiblemente de una multiplicidad de elementos desencadenantes para que inicie un proceso agroecológico a gran escala.

Cuando el movimiento CaC comenzó en Nicaragua a mediados de 1980, el país estaba en guerra, económicamente embargado por Estados Unidos, y sufría de suelos degradados, bajos rendimientos, una profunda escasez de alimentos e hiperinflación sin precedentes (Vásquez \& Rivas, 2006). En Cuba, el movimiento agroecológico ganó prominencia en el contexto de la caída del bloque soviético, el incremento del bloqueo económico 
estadounidense, la escasez generalizada de alimentos y el agotamiento del modelo industrial (Machín Sosa et al., 2010; 2013; Rosset et al., 2011). En Chiapas, la crisis del sector cafetalero a finales de 1990 se debió a la confluencia de altos costos de insumos, rendimientos decrecientes, colapso de los precios internacionales del café y el desmantelamiento del IMECAFE (HernándezCastillo \& Nigh, 1998; Martínez-Torres, 2006). En India, la crisis estuvo marcada por un alarmante endeudamiento campesino que llevó a una epidemia de suicidios sin precedentes - un promedio del suicidio de un agricultor cada 30 minutos- junto con los bajos ingresos, debido a la caída de los precios del mercado y al aumento de los costos de los insumos de la revolución verde (Mohanty, 2005; Vyas, 2005; Misra, 2008; Vakulabharam, 2013; Khadse et al., 2017).

Estas crisis crearon oportunidades políticas y propiciaron contextos para alternativas al modelo agroindustrial. Fue en el marco de estos escenarios en el que las semillas de la masificación de la agroecología pudieron germinar, y entonces ser cuidadas y nutridas por el conjunto de factores interactivos que describimos a continuación.

\subsection{Impulsor dos: organización social y proceso social intencional}

La organización es el medio de cultivo sobre el cual crece la agroecología y las metodologías sociales aceleran este crecimiento (Rosset, 2014; Rosset \& Altieri, 2018). Imaginemos una familia campesina que no es parte de ningún tejido organizativo. La familia puede transformar su granja agroecológicamente, pero es posible que otros agricultores no tengan una manera de aprender o emular la experiencia de aquella familia. En contraste, si esa familia es parte de una organización que realiza intercambios de $\mathrm{CaC}$, estos intercambios podrían tener fácilmente un efecto multiplicador.

La experiencia de los movimientos sociales rurales y las organizaciones de agricultores y campesinos indican que el nivel de organización -llamado "organicidad" por los movimientos sociales- es un elemento clave para llevar la agroecología a mayor escala, como es la extensión de metodologías sociales horizontales basadas en el protagonismo de campesinas y campesinos para construir procesos sociales colectivos. Las propias organizaciones campesinas patrocinan, cada vez más, escuelas de agroecología y procesos de $\mathrm{CaC}$ (Rosset et al., 2011; Rosset \& Martínez-Torres, 2012; Rosset, 2014; McCune et al., 2016; 2017).

La organización y los procesos sociales juegan un rol clave en cada uno de los cinco casos revisados en este artículo. Ese rol es evidente en los casos de Nicaragua y Cuba, donde la metodología $\mathrm{CaC}$ llevó a un escalamiento rápido de la agroecología (Holt-Giménez, 2006; Rosset et al., 2011). Hemos argumentado en otra parte que la extensión de la agroecología fue mucho más rápida en Cuba que en América Central, debido al mayor grado de organicidad de la ANAP y la mayor internacionalidad con que esta asumió y promovió la metodología $\mathrm{CaC}$ (Rosset et al., 2011).

Hemos también argumentado que la ZNBF despegó en el estado de Karnataka porque echó raíces en comunidades que ya tenían un rico tejido organizativo proporcionado por la KRRS (Khadse et al., 2017). En Chiapas, Martínez-Torres (2006) ha mostrado que un ciclo anterior de formación de capital social, por parte de las cooperativas de 
campesinos productores de café, sentó las bases para la rápida adopción de métodos de cultivo orgánico y para la apropiación por parte de las cooperativas de nuevos mercados que se abrieron al café certificado. En Brasil, la red de Ecovida es, en efecto, una estructura organizativa basada en un proceso social y una metodología que conecta cooperativas de agricultores y consumidores existentes (Lamine et al., 2012). En todos los casos, la organización social y sus procesos fueron factores que hicieron posible el escalamiento.

\subsection{Impulsor tres: prácticas agroecológicas simples y efectivas}

La reducción de insumos sintéticos (por ejemplo, mediante la gestión integrada de la fertilidad de suelos y control de plagas) y sustitución de insumos (pesticidas microbianos y biofertilizantes comprados) pueden ser eslabones en la transición hacia el sistema agroecológico. Esto es lo que Gliessman (2015) llama agroecología niveles 1 y 2: la reducción de insumos industriales y la sustitución de prácticas convencionales con prácticas agroecológicas, respectivamente. Sin embargo, un sistema agroecológico ocurre en el nivel 3: aquel en el que se integran los diversos elementos del agroecosistema. El nivel agroecológico 3 requiere la creación de fortalezas y mecanismos autónomos para el mantenimiento de la fertilidad de los suelos y la regulación de plagas y malezas, así como también sinergias y complementariedad en el uso del espacio, nutrientes, agua y luz solar (Gliessman, 2015). Dichas prácticas agroecológicas se basan en el mantenimiento de la vida en el suelo, el mejoramiento de la biodiversidad agrícola-como la integración de cultivos, árboles y ganado- y el rediseño a nivel de fincas y paisajes -policultivos, conservación de suelos, conservación de bosques o parches de vida silvestre- (Perfecto et al., 2009; Gliessman, 2015).

En sus respectivas fases iniciales, la ZBNF en India y la revolución agroecológica en Cuba (dirigida por la ANAP), se basaron primeramente en la práctica de sustitución de insumos, incluyendo biofertilizantes, microorganismos eficientes, pesticidas botánicos, control de agentes biológicos, y, en Cuba, de composta con lombrices. Las prácticas agroecológicas más integradoras (nivel 3 ), promovidas en nuestros casos, incluyeron el uso de abono orgánico y estiércol de ganado nativo, con la ZNBF, para enriquecer y proteger el suelo y para cerrar los ciclos de nutrientes. De manera similar, Ecovida promovió la incorporación de materia orgánica, la prevención de la erosión y el uso de abonos verdes. Agricultores en Cuba, Chiapas y América Central usaron abonos verdes, incorporación de materia orgánica, setos y barreras de contorno. Los agricultores de café orgánico en Chiapas también utilizaron composta, regeneración microbiana de los suelos, mantillo y manejo de malezas para prevenir la erosión de los suelos.

Para incrementar la biodiversidad y las funciones relacionadas con los agrosistemas relacionados a nivel de fincas, los movimientos que describimos en India, Chiapas y Cuba promueven el policultivo y el sistema silvopastoril, como la diversificación de árboles de sombra en plantaciones de café, integración del ganado con cultivos y árboles e integración de árboles frutales con diversificación de caña de azúcar. Las organizaciones brasileñas y cubanas fomentan la selección, producción e intercambio de semillas 
locales. No hemos encontrado evidencia de que los movimientos que estudiamos promuevan la protección y restauración de áreas silvestres al interior o cerca de los ambientes agrícolas, aunque esa práctica es importante para mantener la función del agroecosistema (confr. Perfecto et al., 2009).

A pesar de la ausencia frecuente de prácticas integradoras a nivel de fincas y paisaje, los esfuerzos de masificación observados en los cinco casos han reducido los insumos externos y los costos de producción, al mismo tiempo que aumentan la producción. Por ejemplo, los agricultores de la ZBNF han logrado mejores rendimientos usando menos agua y menos insumos externos (Khadse et al., 2017). En Nicaragua, miembros del movimiento $\mathrm{CaC}$ vieron disminuir sus costos, mientras que sus rendimientos aumentaron en un 300\% (HoltGiménez, 2006).

El análisis de estos casos sugiere que las prácticas y recetas simples, en el nivel 2, pueden ser importantes para una adopción temprana. Las prácticas más complejas que dependen de una comprensión más sofisticada de las relaciones ecológicas en las propiedades agrícolas y los niveles de paisaje avanzan a un ritmo más lento. Como lo demuestra la rápida adopción de los paquetes de la revolución verde, las tecnologías que dan resultados rápidos y visibles atraen a los agricultores. El manejo agroecológico más complejo, las prácticas que acumulan beneficios más lentamente y las que requieren coordinación a nivel de ambiente pueden ser más difíciles de promover, en particular porque sus beneficios, aunque sustanciales, pueden ser difusos y difíciles de observar. Es por esto por lo que la metodología $\mathrm{CaC}$ tiene como uno de sus principios comenzar lentamente y con prácticas simples capaces de entregar resultados rápidos. Un éxito temprano motiva a los agricultores a adherirse al proceso e introducir gradualmente prácticas más complejas (Holt-Giménez, 2006; Machín Sosa et al., 2013).

\subsection{Impulsor cuatro: proceso enseñanza-aprendizaje constructivista}

El proceso de enseñanza-aprendizaje utilizado por los movimientos que han masificado la agroecología promueve la inclusión activa del conocimiento tradicional/local/contemporáneo, así como el desarrollo de la autonomía. La pedagogía es predominantemente horizontal. Por ejemplo, en los cinco casos se utilizó la metodología de $\mathrm{CaC}$, acorde a los principios constructivistas ${ }^{6}$ de Paulo Freire (Freire, 1970; Holt-Giménez, 2006). Estos métodos de enseñanza garantizan colectividad, aprendizaje horizontal, discusiones diversas en una cocreación de conocimiento (Coolsaet, 2016), y "diálogo de saberes", es decir: diálogo entre distintos conocimientos y formas de conocer (MartínezTorres \& Rosset, 2014). El objetivo común es el reconocimiento del saber campesino y el cultivo de su protagonismo, en contraste con el enfoque del extensionismo de la agricultura convencional, en la que los campesinos juegan un rol pasivo (Scoones \& Thompson, 1994; Holt-Giménez, 2006; Altieri \&

\footnotetext{
6 Delval (2000, p. 78) considera que el constructivismo es “una posición psicológica y epistemológica que trata de explicar cómo se forma el conocimiento [...] El constructivismo propone que los sujetos necesitan construir su conocimiento y que el conocimiento no puede darse ya construido. Esta teoría establece que los sujetos forman su conocimiento basándose en el conocimiento que ya tienen, evaluándolo y contrastándolo con su realidad física y social".
} 
Toledo, 2011; Rosset et al., 2011). Los cinco casos emblemáticos se basan en prácticas tradicionales y locales, especialmente para el rescate de variedades de semillas nativas y razas de animales.

El proceso de enseñanza-aprendizaje en los casos que estudiamos integran componentes espirituales, emocionales e ideológicos con capacitación técnica, lo que permite a las personas experimentar un aprendizaje significativo (Ausubel, 1983). Por ejemplo, el método de $\mathrm{CaC}$ demanda trabajo con "la cabeza, el corazón y las manos", lo que significa aglutinar elementos cognitivos, emocionales y prácticos (Holt-Giménez, 2006). El componente espiritual es evidente en el auge del café orgánico en Chiapas y en el movimiento $\mathrm{CaC}$ en Mesoamérica, ambos influenciados fuertemente por la práctica ver- reflexionar-actuar de la teología de la liberación y la cosmovisión indígena (Boff, 1994). De manera similar, la ZBNF está arraigada en valores espirituales que permiten a los campesinos conectarse a la práctica agroecológica. En los cinco casos, los procesos de enseñanza- aprendizaje son acompañados por una postura ideológica clara. Los programas educativos incluyen en cada caso análisis sistémico de macronivel socioeconómico, cultural y contextos políticos. Estas prácticas pedagógicas resuenan con la teoría sociocultural de Vigotsky, la cual establece que la interacción social, la cultura y el contexto histórico, juegan un rol fundamental en el desarrollo de la cognición (Carrera \& Mazzarella, 2001; McCune et al., 2016).

Aunque la Red Ecovida y el movimiento $\mathrm{CaC}$ de Mesoamérica colaboraron con las escuelas locales, el énfasis en los cinco casos es en la educación informal. Así, la mayor parte de la capacitación tiene lugar fuera de las instituciones formales, utilizando metodologías coherentes con la pedagogía crítica, el protagonismo campesino y la autonomía. Los elementos significativos incluyen el uso de materiales adecuados para las condiciones locales, visitas mutuas entre campesinos y actividades prácticas en lugares significativos, como sus propios campos, que hacen que el aprendizaje sea significativo. Las metodologías se basan en la enseñanza mediante el ejemplo; lo que los maestros a menudo llaman "modelado ético y práctico" (McLaren, 2001, p. 79).

Esta pedagogía del ejemplo es comprendida por los movimientos sociales en América Latina como una continuación del pensamiento de José Martí y Ernesto "Che" Guevara (Turner, 2007; Barbosa \& Rosset, 2017). Por ejemplo, grupos de capacitación visitan fincas que emplean prácticas agroecológicas eficientes, porque el hecho de ver resultados de primera mano inspira a los campesinos a emular estas prácticas. Como dice Holt-Giménez (2001, p. 27):

Los campesinos aprenden uno de los otros compartiendo sabiduría, creatividad y conocimiento, no sólo información y técnicas. En lugar de simplemente transferir tecnologías, los campesinos primero y ante todo, "hacen cultura" -el intercambio que deriva en acción construye una cultura de agricultura sostenible-. La transferencia de tecnologías es en realidad sólo un efecto -y no siempre el principal- de esta matriz cultural.

El proceso de enseñanza-aprendizaje usado en los cinco casos es apoyado con materiales auxiliares que incluyen libros, folletos, programas de radio y televisión, e incluso un intercambio intenso de ideas en redes sociales tales como Facebook (en India) y comunicación a través de teléfono celular (Khadse et al., 2017). Los elementos 
pedagógicos de la expansión de la agroecología estimulan la creatividad de las personas, así como su participación y completo reconocimiento de sí mismos y otros como sujetos (McCune et al., 2016; 2017; Brescia, 2017). En McCune et al. (2016), argumentamos que las organizaciones campesinas están implementando estas pedagogías críticas de modo que usan el territorio en sí como mediador pedagógico para llevar la agroecología a escala.

\subsection{Impulsor cinco: discurso movilizador}

La teoría sobre la acción colectiva ha identificado que el discurso es un elemento clave en los procesos de movilización social, cuando es capaz de definir un problema común, un adversario al cual oponerse, un horizonte de lucha, y una identidad y principios comunes (Touraine, 1994). La capacidad de establecer un discurso, o marco fácilmente comprensible, que ayude a promover la acción social, de forma que sea entendido y reproducido por el colectivo, constituye un aspecto importante para el escalamiento de la agroecología. Los movimientos agroecológicos exitosos combinan la agroecología como prácticas agrícolas que funcionan con la agroecología como un marco discursivo que moviliza. Este último motiva a las familias campesinas y agricultoras a emprender transformaciones agroecológicas a menudo difíciles (Rosset \& Martínez-Torres, 2012; Martínez-Torres \& Rosset, 2014).

En todos los casos analizados, el discurso ha estado fuertemente politizado en contra del sistema agroindustrial de la revolución verde. Sin embargo, para que el discurso agroecológico resulte efectivo se requiere que esté situado en los horizontes culturales y concuerde con cada contexto específico. Por ejemplo, el discurso ZBNF de Palekar amalgama una crítica del sistema explotador, anticampesino, dominado por las corporaciones transnacionales y la cultura occidental, con metáforas de la mitología hindú y los principios de Gandhi de cambio personal, vida austera, no violencia y responsabilidad con la Madre Tierra (Khadse et al., 2017). En Cuba, la crítica contra el modelo agroindustrial se hibrida con los valores socialistas de la revolución, el discurso de José Martí, el orgullo de ser campesino, la soberanía alimentaria y el cuidado de la naturaleza (Machín Sosa et al., 2010; 2013).

Por su parte, el discurso movilizador en el movimiento del café en Chiapas y el movimiento $\mathrm{CaC}$ en Mesoamérica, se encuentra influenciado por la teología de la liberación, cuestionando fuertemente el patrón de desarrollo en curso y la ruta tecnológica de la revolución verde, al tiempo que lo entremezcla con valores que promueven la autonomía, el amor a la Madre Tierra, la defensa del territorio y la cultura, y el retorno a los saberes ancestrales de los pueblos mesoamericanos (Hernández-Castillo, 2010). En el sur de Brasil, otra región fuertemente influenciada por la teología de la liberación, el discurso de Red Ecovida contra los agroquímicos, la comercialización de alimentos industrializados en grandes supermercados y la promoción del cuidado de la naturaleza y la salud, ha ayudado a crear una identidad compartida entre los movimientos de consumidores y los agricultores agroecológicos.

En resumen, cada uno de los cinco casos está marcado por un discurso movilizador que se ha basado en principios culturales y espirituales contextualmente apropiados que reconocen el 
valor de los campesinos y los pueblos indígenas. Cada discurso ha sido efectivo porque motiva a los miembros de los movimientos a oponerse al sistema agroindustrial y tomar la agroecología como la alternativa al modelo nocivo de la revolución verde.

\subsection{Impulsor seis: aliados externos}

Los aliados externos han desempeñado un papel vital en cada caso estudiado. Los recursos y el apoyo que los aliados aportan al proceso de escalamiento toman una variedad de formas: publicidad; material (ej., fondos); moral (ej., legitimidad social) y acompañamiento organizativo o humano (ej., conocimientos, habilidades y voluntarios). El apoyo de los aliados procede de varias áreas que incluyen el gobierno, los medios de comunicación, el mundo académico, los partidos políticos, las instituciones religiosas y las ONG. Los aliados comprenden instituciones y, más comúnmente, funcionarios amigos dentro de instituciones que normalmente no apoyan la agroecología, pero que gracias a su labor contribuyen a reorientar recursos públicos.

Los aliados clave del movimiento ZBNF son los ashrams hindúes que proveen alojamiento y alimentación gratuita para las sesiones de formación, así como legitimidad social. También el movimiento campesino ha brindado apoyo organizativo, difundiendo la agroecología a través de su estructura de base. Asimismo, individuos conocedores de las nuevas tecnologías han brindado apoyo comunicativo a la ZBNF con amplia presencia en internet a través de varios blogs, foros, y otros sitios web, donde se producen intercambios entre agricultores rurales y urbanos. Por su parte, algunas tiendas ofrecen espacios de mercado favorables. También pueden contarse algunos individuos influyentes, incluidos algunos empresarios, políticos, actores y funcionarios gubernamentales, quienes han dado visibilidad al movimiento en los principales medios de comunicación y han impulsado políticas públicas favorables (Khadse et al., 2017).

Los aliados esenciales del movimiento $\mathrm{CaC}$ en América Central fueron las ONG y organizaciones campesinas que trajeron ideas, fondos y recursos organizacionales. El movimiento comenzó con apoyo financiero y técnico de Vecinos Mundiales y Pan para el Mundo (Holt-Giménez, 2006). En Nicaragua el apoyo de las iglesias protestantes alemanas y católicas jugó un papel importante (Salazar, 2014). Asimismo, los participantes también identifican el apoyo de las ONG como clave para introducir una perspectiva de equidad de género en el movimiento (Holt-Giménez, 2006).

En Cuba varias instituciones de gobierno han sido importantes aliadas del Movimiento $\mathrm{CaC}$. En particular, políticas públicas de apoyo, como la reforma agraria, fueron precondiciones clave para el éxito de $\mathrm{CaC}$. Asimismo, organizaciones campesinas aliadas en Centroamérica, apoyadas por ONG internacionales, fueron fundamentales para introducir la metodología de $\mathrm{CaC}$ en Cuba a fines de los años noventa. Las ONG y las universidades han proporcionado investigación, asistencia técnica y otros tipos de apoyo. También pueden enumerarse grupos como la Asociación Cubana de Técnicos Agropecuarios y Forestales (ACTAF), la Asociación Cubana de Producción Animal (ACPA) y el Programa de Innovación en Agricultura Local del sector público internacional-nacional, los cuales jugaron roles similares. Aunque si bien es cierto que la ideología dominante del Ministerio de Agricultura 
sigue siendo la de la agricultura industrial a gran escala, el movimiento ha logrado incidir en tener varias políticas públicas favorables, "al menos hasta que se normalicen las relaciones comerciales". Por ahora, Cuba tiene unas de las políticas más favorables del mundo para la agroecología (listado en Machín Sosa et al., 2010; 2013).

El movimiento brasileño de agroecología, por su parte, creció como una alianza de ONG promotoras de la agricultura alternativa, miembros de iniciativas locales de agricultura ecológica y organizaciones de agricultores, enlazamiento al que pronto se unió la Federación de Agricultores Familiares (FETRAF). Posteriormente, el Movimiento de Trabajadores Sin Tierra (MST) (miembro de la LVC) agregó su fuerza y sus miembros al movimiento. Posteriormente, la alianza ayudó a crear la Asociación Brasileña de Agroecología (ABA) y la Articulación Nacional de Agroecología (ANA), ambas agrupaciones nacionales de ONG, movimientos y científicos agroecológicos. Redes regionales como Red Ecovida en el sur de Brasil se formaron como asociaciones entre agricultores, científicos, consumidores y algunas instancias del gobierno para establecer sistemas alimentarios agroecológicos localizados. Estas alianzas han fortalecido la capacidad del movimiento para reaccionar ante las oportunidades políticas y abogar por políticas favorables.

Por último, en Chiapas, México, la influencia del clero presbiteriano y católico adherido a la teología de la liberación y la teología india, fue fundamental para promover el café orgánico como parte de un renacimiento de la cultura tradicional maya. Vital fue también la captura de la infraestructura de procesamiento de café por parte de las cooperativas campesinas (ayudadas por la simpatía de funcionarios del gobierno) cuando se privatizó el IMECAFE.

En resumen, los cinco casos muestran que los aliados externos juegan un papel clave en la masificación de los movimientos agroecológicos, apoyando a los agricultores y campesinos, canalizando recursos, motivando articulaciones entre sectores sociales y fortaleciendo la capacidad de negociación. Sin embargo, puede que haya una línea fina entre usar el apoyo de los aliados para construir la fuerza interna de procesos autónomos de abajo arriba, y la creación de altos niveles de dependencia en actores y/o políticas externas que ponen en peligro el medio y la sostenibilidad a largo plazo del proceso (Rosset \& Altieri, 2018).

\subsection{Impulsor siete: construcción de mercados favorables a la agroecología}

El desarrollo de redes alimentarias alternativas (RAA) no es una condición necesaria para la adopción y adaptación generalizada de prácticas agroecológicas por parte de los agricultores, como muestra su ausencia en los casos de la ZBNF en India y $\mathrm{CaC}$ en Nicaragua. Sin embargo, en muchos casos, los mercados son una arena sociopolítica estratégica para escalar la agroecología (Pretty, 2001; Hebinck et al., 2014). Para Gliessman (2015), construir "ciudadanía alimentaria" a través de la participación en las RAA es el cuarto nivel de conversión agroecológica. Acuerdos recíprocos como las redes de solidaridad a menudo han sido fundamentales para el avance de los mercados de agricultores ecológicos y la viabilidad socioeconómica de la agroecología (Granovetter, 2005; Van Der Ploeg, 2012; Parmentier, 2014; 
Gliessman, 2015; Henderson \& Casey, 2015; LVC, 2015).

Estos acuerdos de mercado pueden ser impulsados por consumidores de productos internacionalizados, como en el caso del café de comercio justo certificado y ecológico producido en Chiapas (Martínez-Torres, 2006). Los arreglos también pueden sustentarse en los mercados de alimentos locales y regionales, como los organizados por Red Ecovida en Brasil. Alternativamente, pueden ser impulsados por políticas públicas que apoyan a los pequeños agricultores y la producción agroecológica, como en los casos del fuerte apoyo en Cuba a la creación de cooperativas y los acuerdos para comprar su producción como en el Programa de Adquisición de Alimentos (PAA) en Brasil (Wittman \& Blesh, 2017). Los efectos socioeconómicos y ecológicos pueden variar según los acuerdos de mercado, pero arreglos que resultan útiles para la masificación de la agroecología contribuyen a la transformación del sistema alimentario mediante la diferenciación de la producción agroecológica frente a las mercancías del mercado general.

La difusión de la producción de café ecológico y de comercio justo en Chiapas ha sido claramente provocada por el mercado, con la creación de cooperativas comercializadoras campesinas y la llegada en 1990 de compradores europeos en busca de producción de café orgánico (MartínezTorres, 2006). Dado que el café ha demostrado ser vulnerable a factores externos, tales como los vaivenes del mercado y las enfermedades de los cultivos, en los últimos años las cooperativas están buscado diversificar. Este esfuerzo se refleja en su búsqueda de otros productos de comercio justo, como la miel, así como alimentos para autosuficiencia y para mercados locales. El caso cubano ejemplifica una fuerte participación del Estado en la gestión del mercado de alimentos, apoyando la formación de cooperativas de agricultores a lo largo del país y otorgándoles contratos de compra para asegurarles precios de los cultivos que dan garantías de mercado a los agricultores. Estos acuerdos de mercado en Cuba contribuyen a la persistencia y al crecimiento de los procesos de crecimiento que se originan en los factores descritos anteriormente. La Red Ecovida ejemplifica un movimiento de agroecología formado alrededor de una RAA. A través de acciones que incluyen circuitos de mercados que conectan productores y consumidores y una red de producción local de semillas, Ecovida se ha convertido en la principal plataforma social para un movimiento de economía solidaria que abarca tres estados en el sur de Brasil (Rover, 2011; PérezCassarino, 2012; Rover et al., 2016). La estructura descentralizada y horizontal de Ecovida articula diversos actores a través de acuerdos de mercado para productos agroecológicos que transforman sistemas alimentarios locales y regionales.

Los múltiples mecanismos de mercado utilizados para fortalecer los movimientos agroecológicos corresponden a la necesidad de innovación social adaptada a diferentes situaciones y retos. Aunque cuestionamos que las RAA sean una condición necesaria, las condiciones del mercado pueden determinar el ritmo al que la agroecología pueda crecer y expandirse. Los casos que estudiamos nos llevan a sugerir que el potencial transformativo aumenta cuando los movimientos utilizan los mercados como esferas de acción sociopolíticas. Este proceso no depende necesariamente de la intervención estatal, aunque los movimientos sociales creados en torno a estas 
estrategias de mercado pueden influir en prácticas estatales y políticas públicas.

\subsection{Impulsor ocho: politicas favorables y oportunidades políticas}

Las políticas, incluidas las iniciativas del sector público y privado, pueden complementar y mejorar los esfuerzos para escalar la agroecología (Parmentier, 2014). Los ejemplos más significativos incluyen la reformulación y retracción de políticas que apoyan la reproducción del modelo agroindustrial, y en su lugar que apoyen políticas sustentadas en los principios agroecológicos. Ejemplos incluyen programas para la agricultura familiar y pequeños agricultores en Brasil y Cuba.

La participación del Estado ha estado presente en todos nuestros casos de escalamiento o institucionalización de la agroecología, pero a diferentes niveles. Políticas que aseguran el acceso a la tierra y a los distintos tipos de reforma agraria establecen las condiciones necesarias para el escalamiento. En el movimiento de café orgánico de México, el Estado tenía una participación limitada, y el desmantelamiento de un programa de mercadeo estatal creó una oportunidad política, permitiendo a las organizaciones campesinas influir en los acuerdos de mercado y marcos regulatorios. Del mismo modo, el movimiento ZBNF en India surgió de otro de agricultores y el gobierno respondió solo después de que el movimiento ganase fuerza, proporcionando recursos para una escuela de agroecología campesina. En los casos cubano y brasileño, las acciones de los movimientos sociales, incluyendo las organizaciones y sindicatos campesinos, ganaron un apoyo significativo estatal, incluyendo políticas públicas para reforzar las estrategias del movimiento que contribuyen a la escalada agroecológica.

Ninguna política emerge como esencial; en la práctica se requiere una combinación de políticas complementarias para abordar varios elementos fundamentales en la transformación de los sistemas agroalimentarios. En Cuba, los científicos y los agricultores pidieron políticas públicas para los sectores de producción agrícola, educación y comercio para fortalecer la agroecología. Los ejemplos abarcan programas para promover el control biológico, agricultura urbana, reciclaje de materia orgánica, reproducción de plantas de manera participativa, ganado en el patio trasero, cambios en la currícula escolar, obtención de productos agrícolas por el gobierno, nuevos pasos en las políticas de reforma agraria que proveyeran a los campesinos con tierra que no era utilizada (Machín Sosa et al., 2010; 2013). Estas políticas enfocadas agroecológicamente prosperaron en el contexto de políticas nacionales que mantenían altos estándares de educación, salud y capacidad técnica de los agricultores, así como políticas del Periodo Especial para garantizar el acceso a tierra, crédito y mercado a los agricultores.

El Partido de los Trabajadores (PT) en el gobierno de Brasil también adoptó una larga lista de políticas para apoyar las prácticas agroecológicas (Caporal \& Petersen, 2011; Petersen et al., 2013), sin embargo, estas políticas nunca amenazaron la posición dominante del sistema agroindustrial y muchas de ellas están desapareciendo con el nuevo gobierno que se impuso con un golpe de Estado (Oliveira \& Baccarin, 2016; Rosset \& Altieri, 2018). Lo último refuerza la preocupación de que el apoyo de las políticas públicas puede 
crear dependencias que debiliten a largo plazo a los movimientos sociales. En Brasil la suspensión de políticas que apoyaban a las cooperativas y los incipientes proyectos de agroindustria familiar, significa que estas empresas actualmente tienen dificultades para cubrir sus costos de producción (Oliveira \& Baccarin, 2016).

La coherencia entre políticas es fundamental (Parmentier, 2014), y la profundidad de los cambios en las políticas para una transformación sistemática aún tiene que materializarse. Por ejemplo, en Brasil, un enorme país con una fuerte economía sustentada en la exportación agrícola, diversos grupos socioeconómicos han ganado espacio para sus intereses, incluyendo los campesinos y las familias agrícolas. Sin embargo, las políticas que han ganado del Estado son diminutas en comparación con el apoyo que brinda a los agronegocios (Itaboraí, 2013). Los agricultores de pequeña escala compiten en bases desiguales, porque las políticas que intentan promover la agricultura familiar y la agroecología están en contradicción con políticas más arraigadas que apoyan la agricultura a gran escala de monocultivos. Una situación similar se observa en Cuba, en donde muchas políticas nacionales actualmente apoyan la agroecología, pero la política para la agricultura industrial domina la agenda del Ministerio de Agricultura, que tiene la esperanza de que las relaciones comerciales se normalicen.

\section{Discusión}

Los cinco casos de masificación de la agroecología se han desencadenado en un contexto de crisis y ha sido impulsada por fuertes estructuras organizativas de movimientos sociales capaces de canalizar la respuesta colectiva a esas crisis. Este tipo de procesos se fortalecen cuando se utilizan métodos pedagógicos constructivistas, los agricultores reconocen la eficacia de las prácticas agroecológicas, y las alianzas refuerzan el impulso. Además de esto, los mercados y las políticas favorables extienden las oportunidades para la transformación del sistema agroalimentario.

Aunque la importancia relativa de los impulsores del escalamiento agroecológico en cada uno de los cinco casos varía, hemos detectado algunos patrones. Posiblemente el más importante es que el escalamiento de la agroecología es multidimensional; es el producto de la convergencia de varios factores. La crisis estuvo presente en todos los casos estudiados y en cierta medida parece haber puesto en marcha el proceso de expansión de la agroecología. Sin embargo, la respuesta exitosa ante las crisis, y las oportunidades que se abren, requieren de una organización de base preexistente, fuerte y bien desarrollada.

En efecto, el tejido organizativo constituye el medio de cultivo sobre el cual crece la agroecología. Es la estructura por la que circulan aprendizajes, valores, significados y horizontes de acción política. Así mismo, provee las oportunidades para diseñar e implementar los procesos tipo $\mathrm{CaC}$ y vincularlos con aliados externos. No obstante, la "estructura organizativa" no debe concebirse como estática, sino saber que puede crecer a medida que la agroecología se expande y articula organizaciones más pequeñas para extender su alcance; como ocurrió en el caso de la Red Ecovida. Asimismo, las estructuras organizativas no tienen que ser formales. En India, por ejemplo, el movimiento ZBNF creció a través de una red 
organizativa parcialmente espontánea por medio de interacciones no institucionalizadas. De hecho, muchos agricultores practican la agroecología sin haberse unido a alguna organización. Sin embargo, la participación de organizaciones puede determinar en gran medida el escalamiento de la agroecología (Rosset et al., 2011).

También, la pedagogía constructivista y las metodologías horizontales tipo $\mathrm{CaC}$, parecen ser cruciales para hacer crecer la agroecología territorialmente. El crecimiento y expansión de la agroecología y la transformación de prácticas productivas se han logrado gracias a estos métodos que se sustentan en el diálogo de saberes. De acuerdo con Rosset et al. (2011, pp. 168-169):

Los métodos en los cuales el extensionista o el agrónomo es el actor principal y los agricultores juegan un rol pasivo, se limitan, en el mejor de los casos, a la cantidad de familias campesinas que pueden ser efectivamente atendidas por cada técnico, porque se genera muy poca o ninguna dinámica catalizadora intrínseca que promueva, entre los mismos campesinos, la realización de innovaciones más allá del técnico. Un principio fundamental de $\mathrm{CaC}$ es que los agricultores tienen más probabilidades de creer y emular a un compañero agricultor, que está utilizando con éxito una determinada alternativa en su propia granja, que tomar la palabra de un agrónomo de posible extracción urbana. Si bien un extensionista convencional puede desmovilizar a los campesinos, $\mathrm{CaC}$ los moviliza, a medida que se convierten en los protagonistas del proceso de generar y compartir sus propias tecnologías.

Los campesinos promotores necesitan una formación minuciosa en la metodología, debido a que tienden a copiar el ejemplo de los expertos de los programas de extensión, quienes imponen en lugar de facilitar, prescribiendo métodos en vez de promover procesos participativos (Machín Sosa et al., 2010; 2013). Cuando los campesinos promotores actúan como extensionistas institucionales, el proceso generalmente se mantiene centralizado en pocos agricultores y pierde impulso. Por lo tanto, es esencial que las prácticas agroecológicas y las pedagogías críticas marchen de la mano, de modo que las nuevas propuestas puedan adaptarse a nuevos contextos.

En la mayoría de los cinco casos analizados, las estrategias de sustitución de insumos fueron atractivas para los campesinos. Sin embargo, insistimos en que los movimientos agroecológicos necesitan moverse más allá de la sustitución de insumos para beneficiarse de las interacciones sinérgicas en sistemas agroecológicos totalmente integrados (Vandermeer \& Perfecto, 1997; Morales, 2002; Gliessman, 2015), como ha sido el caso cubano (Rosset et al., 2011). Estas observaciones hacen plantearnos algunas preguntas sobre los procesos de transición: ¿será posible iniciar con mayor complejidad y hacer énfasis en la prevención? o ¿será mejor captar primero la atención de los campesinos con resultados rápidos gracias a la sustitución de insumos? ¿Enfocarse en la sustitución de insumos podría perpetuar el pensamiento lineal causa-efecto propio de las "recetas" de la agronomía convencional? ¿La práctica agrícola vinculada con las cosmovisiones tradicionales pueden promover el pensamiento y prácticas complejas, a través de formas de conocimiento que reconozcan la interactividad entre los elementos agroecológicos? (Aldasoro, 2012).

Los procesos que hemos estudiado fueron protagonizados y liderados por organizaciones campesinas. De hecho, el protagonismo campesino está en el centro, tanto en los movimientos 
campesinos como en la agroecología, lo que conduce a una afinidad natural entre los dos. Van Der Ploeg (2013) sugiere, y nuestros casos lo corroboran, que la agroecología atrae a los campesinos en parte porque disminuye su dependencia y construye su autonomía. Por ello, los movimientos agroecológicos son más fuertes cuando no dependen excesivamente de estructuras externas, ni de proyectos de ONG, instituciones académicas, o programas de políticas públicas. Por el contrario, los movimientos agroecológicos promueven la conformación constante del liderazgo campesino, lo cual les brinda impulso y fortaleza.

A pesar de ello, en los casos analizados el papel de los aliados externos ha sido importante. Una lección aprendida es que, si bien es necesario que la dirección del proceso esté en manos de las organizaciones campesinas, los aliados externos pueden jugar un rol fundamental contribuyendo con aspectos específicos que las organizaciones no logran cubrir adecuadamente por sí mismas. Además, la profunda transformación por la que luchan los movimientos agroecológicos necesitará compartir el costo (ya sea material, político o cultural) entre diferentes grupos de la sociedad civil. Adjudicar todos los esfuerzos requeridos a los agricultores puede imponer un límite en el crecimiento y la expansión de la agroecología. En cierto momento, las alianzas, incluyendo el diálogo de saberes, son elementos fundamentales para fortalecer el conocimiento agroecológico y los enlaces rural-urbanos, así como para influenciar en las políticas y las dinámicas de mercado.

Nosotros, y muchos otros autores, consideramos que la participación de las mujeres es esencial para el escalamiento de la agroecología (Parmentier, 2014; Siliprandi \& Zuluaga, 2014; Siliprandi, 2015).
Aun así, a excepción del movimiento CaC (HoltGiménez 2006), no encontramos en las fuentes de información consultadas que la participación de las mujeres fuera explícitamente fomentada. Sin embargo, las mujeres desempeñan diversos papeles en la agricultura; su responsabilidad tradicional de alimentar a las familias y comunidades y brindar apoyo mental y físico da a las mujeres una profunda y compleja comprensión de los sistemas agroalimentarios (Allen \& Sachs, 2012). Además, las mujeres han asumido el liderazgo en los movimientos para defender y desarrollar la agroecología, resistir contra los modelos agrícolas injustos y luchar contra el despojo territorial (Martínez-Alier, 2002; Siliprandi, 2015; Tait, 2015; Tapia, 2016). Nuestras experiencias de campo nos han llevado a creer que en muchos, o posiblemente en la mayoría de los casos, las mujeres son las que promueven o implementan los cambios agroecológicos en las familias, tanto directamente como influenciando a los hombres (Siliprandi, 2015). Holt-Giménez (2006) señala que las mujeres son frecuentemente las guardianas de la biodiversidad en los campos y huertos, y tienen una fuerte influencia en la decisión sobre el tipo de plantas y variedades a sembrar.

De la misma forma es importante comprender el papel que juega la juventud en los procesos de escalamiento agroecológico. Aunque la juventud no desempeñó un papel fundamental en los casos analizados, los movimientos campesinos actualmente enfatizan el liderazgo y la formación de la juventud (McCune et al., 2014; McCune et al., 2016; 2017; Barbosa \& Rosset, 2017). Los jóvenes que permanecen o regresan al campo suelen tener una visión más agroecológica que la generación anterior. En realidad, las juventudes 
están impulsando la agroecología de manera poderosa (McCune et al., 2016; 2017), y las escuelas agroecológicas están desempeñando un papel muy importante, al brindar a los campesinos jóvenes habilidades técnicas y políticas.

En los casos analizados, las políticas no fueron un impulsor inicial crucial para el escalamiento agroecológico. Generalmente, esas políticas fueron conquistadas a través de demandas o luchas de los movimientos sobre la base de éxitos ya obtenidos. Por ejemplo, la influencia de la ANAP en las políticas cubanas fue proporcional a la habilidad del movimiento de elevar la producción agroecológica, mientras que las políticas brasileñas en favor de la agroecología y la agricultura familiar fueron ganadas a través de la lucha de los movimientos sociales campesinos con el apoyo de ONG y otros sectores. Incluso donde había políticas favorables cuando empezaron los movimientos, estas tendieron a contribuir solamente después de que los procesos de escalamiento ya habían cobrado impulso.

Parmentier (2014, p. 59) argumenta que "desactivar las barreras ideológicas para que haya un reconocimiento político de la importancia socioeconómica y ambiental de los agricultores y la agroecología" es crucial en el proceso de hacer política. Sin embargo, en los casos aquí estudiados, los cambios en las políticas han sido ampliamente marginales. Incluso la incorporación de la soberanía alimentaria en las constituciones de algunos países (por ejemplo, Ecuador) hasta el momento ha tenido un efecto limitado. Los gobiernos de Bolivia, Uruguay y Argentina verbalmente apoyan la agroecología, pero sus políticas económicas dominantes permanecen hostiles (Montagut et al., 2010; Vergara-Camus \& Kay, 2017).
Un riesgo adicional es que las políticas que promueven la institucionalización de la agroecología puedan tener un efecto desmovilizador cuando los procesos de masificación dejan de estar bajo el control de los movimientos sociales (Levidow et al., 2014; Giraldo \& Rosset, 2016; 2017). Otro riesgo asociado con la actual tendencia a la institucionalización de la agroecología en las agendas de la FAO y otras instituciones nacionales o internacionales (Giraldo \& Rosset, 2016; 2017), es la cooptación y captura por parte de los agronegocios ansiosos de pintarse de verde bajo la máscara agroecológica.

El debate sobre las políticas también plantea la cuestión de los mercados. Los casos que exploramos nos llevan a sugerir que mientras los mercados pueden atraer a la gente hacia la agroecología, el escalamiento basado principalmente en las oportunidades de mercado puede ser vulnerable ante cambios externos. Por lo tanto, los mecanismos de mercado deben ser diseñados para fortalecer los movimientos sociales, no para ser una fuerza central del proceso. Los mercados no han sido indispensables para el aumento de la producción agroecológica, pero no tenerlos en cuenta puede resultar siendo un talón de Aquiles para el escalamiento. Los mercados son los que más contribuyen a los movimientos agroecológicos en casos como el de la Red Ecovida y el de la producción de café orgánico de Chiapas, donde están anidados dentro de redes cuyos elementos unificadores son los valores ambientales y sociales. La Red Ecovida asegura el cumplimiento de estos valores a través de un sistema de garantía participativo que construye capacidades y relaciones internas en lugar de perpetuar la dependencia de la certificación externa (Radomsky \& Leal, 2015). 
Las alianzas creadas en torno a los mecanismos de mercado tienen el potencial de ampliar el alcance del poder transformador de la agroecología en ámbitos distintos del de la producción. También observamos que la transformación a gran escala de los sistemas agroalimentarios será difícil hasta que aumente la demanda de productos agroecológicos y hasta que se establezcan relaciones más sólidas entre los productores y los consumidores conscientes.

\section{Conclusiones: ¿un nuevo campo de investigación y construcción de alternativas?}

En este análisis hemos identificado ocho impulsores que fueron importantes, en mayor o menor medida, para la expansión de la agroecología en cinco casos que consideramos emblemáticos. El análisis es preliminar y no abordamos plenamente elementos como el papel de las mujeres y la juventud en las transformaciones de los regímenes alimentarios alternativos. A pesar de ello, consideramos que los patrones revelados contribuyen a la comprensión de la masificación de la agroecología en diversos contextos.

Apenas hemos abordado las interacciones entre las diversas dimensiones del escalamiento agroecológico. Se necesita mucho más detalle sobre cómo estas dimensiones pueden interactuar para generar una retroalimentación positiva. Particularmente, creemos que es importante realizar investigaciones que estudien sistemáticamente cómo las políticas públicas pueden acompañar los esfuerzos existentes, ayudándolos a crecer de manera más autónoma y mejor organizada, en lugar de generar dependencias. También se requiere investigación sobre el papel de las políticas públicas como catalizadores en la aparición de nuevos procesos.

Nos hemos centrado en los aspectos que favorecen la expansión de la agroecología, pero no debemos ignorar la importancia de analizar los elementos que limitan la expansión agroecológica. Estos elementos incluyen relaciones paternalistas, clientelistas y desmovilizadoras; políticas públicas que facilitan la concentración y acaparamiento de la tierra; y acciones gubernamentales, y de instituciones y mercados internacionales que promueven la expansión de los agronegocios y los monocultivos industriales (Giraldo, 2018; Rosset \& Altieri, 2018). Tampoco hemos considerado otros obstáculos como la falta de liderazgo organizativo y de movilización, el poder hegemónico del paradigma de desarrollo de la agricultura dominante, ni los insidiosos efectos de la colonialidad del saber. Necesitamos profundizar la comprensión de cómo hacer crecer y expandir la agroecología en el contexto de la globalización neoliberal, donde estos aspectos limitantes constituyen la regla y no la excepción.

El crecimiento y la expansión de la agroecología es un campo de investigación relativamente nuevo, como un fenómeno en la vida real con gran potencial (Parmentier, 2014; De Schutter, 2010). El caos provocado por el modelo de la revolución verde hace que la expansión sea urgente: la agroecología debe trascender las parcelas individuales, para convertirse en un movimiento a escala territorial, abarcando constelaciones urbanas y rurales, e incluso naciones enteras (Gliessman, 2015; Rosset, 2014; Rosset \& Altieri, 2017), extendiéndose al sistema agroalimentario global: el nivel 5 de la conversión agroecológica propuesta por Gliessman 
(2015). Creemos que esta expansión requiere mayor capacidad de articular los aspectos ecológicos de la agroecología, las ciencias sociales y la investigación transdisciplinaria, con los movimientos sociales que desafían a los agronegocios corporativos y al sistema agroalimentario industrial, haciéndolo inoperante mientras construyen sus propias alternativas (Méndez et al., 2013; Ferguson, 2015).

\section{Referencias}

Aldasoro, E. Documenting and contextualizing Pjiekakjoo (Tlahuica) knowledges through a collaborative research project. Washington D.C., Tesis (Doctorado en Antropología) - University of Washington (UW), 2012.

Allen, P.; Sachs, C. Women and food chains: the gendered politics of food. En: Forson, P. W.; Counihan, C. (Eds). Taking food publics: redefining foodways in a changing world. New York: Routledge, p. 23-40, 2012.

Altieri, M. A. Agroecology: the science of sustainable agriculture. London: Intermediate Technology Publications Ltd, 2. ed., 1995.

Altieri, M. A. Agroecology: principles and strategies for designing sustainable farming systems. Agroecology in action, 2000. Disponible en: <http://www.agroeco. org/doc/ new_docs/Agroeco_principles.pdf $>$. Acceso en: nov. 2017

Altieri, M. A.; Nicholls, C. Scaling up agroecological approaches for food sovereignty in Latin America. Development, 51(4), 472-480, 2008. doi: $10.1057 /$ dev.2008.68

Altieri, M. A.; Nicholls, C. Agroecology scaling up for food sovereignty and resiliency. Sustainable Agriculture Reviews, 11, 1-29, 2012.

Altieri, M. A.; Rogé, P. The ecological role and enhancement of biodiversity in agriculture. En: Lockie, S; Carpenter, D. (Eds.). Agriculture, biodiversity and markets. Livelihood and agroecology in comparative perspective. London: Earthscan, p. 15-32, 2009.

Altieri, M. A.; Toledo, V. M. The agroecological revolution in Latin America: rescuing nature, ensuring food sovereignty and empowering peasants. Journal of Peasant Studies, 38(3), 587-612, 2011. doi: 10.1080/03066150.2011.582947
Ausubel, D. Teoría del aprendizaje significativo. Fascículos De CEIF, 1, 1-10, 1983.

Barbosa, L. P.; Rosset, P. M. Educação do campo e pedagogia camponesa agroecológica na América Latina: aportes da La Via Campesina e da CLOC. Educação e Sociedade, 38(140),705-724, 2017. doi: 10.1590/es010173302017175593

Bhattacharya, N. Food sovereignty and agro-ecology in Karnataka: interplay of discourses, identities, and practices. Development in Practice, 27(4), 544-554, 2017. doi: 10.1080/09614524.2017.1305328

Boege, E; Carranza, T. La Agricultura Sostenible CampesinoIndígena Frente a la Desertificación de la Mixteca Alta. En: Boege, E; Carranza, T. Agricultura sostenible campesinoindígena, soberanía alimentaria y equidad de género: seis experiencias de organizaciones indígenas y campesinas en México. México: PIDASSAA, p. 87-138, 2009.

Boff, C. Epistemología y método de la Teología de la Liberación. En: Ellacuría, I.; Sobrino, J. (Eds.). Mysterium Liberationis. Conceptos fundamentales de la Teología de la Liberación. Madrid, España: Trotta, 2. ed., 1994.

Borras, S., Jr.; Franco, J. C.; Gómez, S.; Kay, C.; Spoor, M. Land grabbing in Latin America and the Caribbean. Journal of Peasant Studies, 39(3-4), 845-872, 2012. doi: 10.1080/03066150.2012.679931

Brescia, S. (Ed.). Fertile ground: scaling agroecology from the ground up. USA: Food First/ Institute for Food and Development Policy, 2017.

Caporal, F. R.; Petersen, P. Agroecologia e políticas públicas na América Latina: o caso do Brasil. Agroecologia, 69, 63-74, 2011. 
Carrera, B.; Mazzarella, C. Vygotsky: Enfoque sociocultural. Educere, 5(13), 41-44, 2001.

Carroll, C. R.; Vandermeer, J. H.; Rosset, P. M. Agroecology. New York: McGraw-Hill, 1990.

Charão, F.; Oliveira, D. Agricultura ecológica al sur de Brasil: de alternativa a contratendencia. Iconos. Revista de Ciencias Sociales, 54, 87-106, 2016.

Coolsaet, B. Towards an agroecology of knowledges: recognition, cognitive justice and farmers' autonomy in France. Journal of Rural Studies, 47, 165-71, 2016. doi: 10.1016/j. jrurstud.2016.07.012

De Schutter, O. Countries tackling hunger with a right to food approach. Significant progress in implementing the right to food at national scale in Africa, Latin America and South Asia. Briefing Note 01, 2010.

De Schutter, O. Agroecology and the right to food. United Nations Special Rapporteur on the Right to Food. Rome: FAO, 2011. Accesible en: http://www.srfood.org/en/reportagroecology-and-the-right-to-food

De Schutter, O. Agroecology, a Tool for the Realization of the Right to Food. En: Lichtfouse, E. (Ed) Agroecology and Strategies for Climate Change. Sustainable Agriculture Reviews 8. Países Bajos, Springer, 2012.

Delval, J. Aprender en la vida y en la escuela. España: Ediciones Morata, 2. ed., 2000.

Ecovida - Rede Ecovida de Agroecologia. Sobre. Accesible en: $<$ https://www. ecovida.org.br $>$. Acceso en: mai. 2017..

Ferguson, B. G. Editorial: Agroecology as a transformative transdiscipline. Ciência \& Tecnologia Social, 2(1), 3-7, 2015. Accesible en: http://periodicos.unb.br/index. php/cts/ article/view/20033/ 14196

Freire, P. Pedagogía del oprimido. Capítulo I. México: Siglo XXI Editores, 1970.

Funes, F.; Vázquez, L. (Eds.). Avances de la agroecología en Cuba. Matanzas, Cuba: Editora Estación Experimental de Pastos y Forrajes Indio Hatuey, 2016.

Giraldo, O. F. Ecología política de la agricultura. Agroecología y posdesarrollo. San Cristóbal de Las Casas: ECOSUR, 2018.
Giraldo, O. F.; Rosset, P. M. La agroecología en una encrucijada: entre la institucionalidad y los movimientos sociales. Guaju, 2(1), 14-37, 2016. doi: 10.5380/guaju.v2i1

Giraldo, O. F.; Rosset, P. M. Agroecology as a territory in dispute: Between institutionality and social movements. Journal of Peasant Studies, 45(3), 545-564, 2017 doi: 10.1080/03066150.2017.1353496

Gliessman, S. R. Transforming food systems to sustainability with agroecology. Journal of Sustainable Agriculture, 35(8), 823-25, 2011. doi: 10.1080/10440046.2011.611585

Gliessman, S. R. Agroecology: the ecology of sustainable food systems. Boca Raton, FL, USA: CRC Press/Taylor and Francis, 3. ed., 2015.

Gonsalves, J. F. Going to scale: what we have garnered from recent workshops? LEISA Magazine, 17(3), 6-10, 2001. Accesible en: http://www.agriculturesnetwork.org/ library/63894

Granovetter, M. The impact of social structure on economic outcomes. Journal of Economic Perspectives, 19(1), 33-50, 2005. doi: $10.1257 / 0895330053147958$

Hebinck, P.; Schneider, S.; Van Der Ploeg, J. D. Rural development and the construction of new markets, v. 12. London: Routledge, 2014.

Henderson, C.; Casey, J. Scaling up agroecology through market systems: using technology justice in agriculture to leave no one behind. Rugby, UK: Practical Action Publishing, 2015. doi: 10.3362/9781780446554

Hernández-Castillo, R. Histories and stories from Chiapas border identities in Southern Mexico. Austin: University of Texas Press, 2010.

Hernández-Castillo, R.; Nigh, R. Global processes and local identity among Mayan coffee growers in Chiapas, Mexico. American Anthropologist, 100(1), 136-147, 1998. doi: 10.1525/aa.1998.100.issue-1

Holt-Giménez, E. Scaling up sustainable agriculture lessons from the Campesino a Campesino movement. LEISA magazine, 17(3), 27-29, 2001.

Holt-Giménez, E. 2006. Campesino a Campesino: voices from Latin America's Farmer to Farmer Movement for sustainable agriculture. Oakland, CA: Food First Books. 
IAASTD - International Assessment of Agricultural Science and Technology for Development. Agriculture at a crossroads. Synthesis report with executive summary: a synthesis of the global and sub-global IAASTD reports. Washington, DC, USA: IAASTD, 2008. Accesible en: https://wedocs.unep.org/handle/20.500.11822/7880

IIRR - International Institute of Rural Reconstruction. Going to scale: can we bring more benefits to more people more quickly? En: Conference report of Workshop Highlights of IIRR. Philippines, Apr. 10-14, 2000.

IPES-Food. From uniformity to diversity: a paradigm shift from industrial agriculture to diversified agroecological systems. International Panel of Experts on Sustainable Food systems, 2016. Accesible en: <www.ipes-food.org>. Acceso en: mar. 2017

Itaboraí, L. Recursos para o agronegócio superam os da agricultura familiar, 2013. Accesible en: <http:// contraosagrotoxicos.org/recursos-para-o-agronegociosuperam-os-da-agricultura-familiar/>. Acceso en: mar. 2017.

Khadse, A. P. M.; Rosset, H. M.; Ferguson, B. G. Taking agroecology to scale: the zero budget natural farming peasant movement in Karnataka, India. The Journal of Peasant Studies, 45, 1-28, 2017.

Lamine, C.; Darolt, M.; Brandenburg, A. The civic and social dimensions of food production and distribution in alternative food networks in France and Southern Brazil. International Journal of Sociology of Agriculture and Food, 19(3), 383-401, 2012.

Lappé, F. M.; Collins, J.; Rosset, P. M. World hunger: twelve myths. New York: Grove Press, 2. ed., 1998.

Levidow, L.; Pimbert, M.; Vanloqueren, G. Agroecological research: conforming - or transforming the dominant agro-food regime? Agroecology and Sustainable Food Systems, 38(10), 1127-1155, 2014. doi: 10.1080/21683565.2014.951459

LVC - La Via Campesina. Declaration of the international forum for agroecology, 2015. Accesible en: <http:// viacampesina.org/en/index.php/main-825issues- mainmenu27/sustainablepeasants-agriculture-mainmenu-42/1749- declaration-of-the-international-forum-for-agroecology $>$. Acceso en: fev. 2015.

Machín Sosa, A., Roque, A. M.; Ávila, D. R.; Rosset, P. M. Revolución agroecológica. El movimiento campesino a campesino de la ANAP en Cuba. La Habana: ANAP y La Via Campesina, 2010. Accesible en: https://viacampesina. org/ downloads/pdf/sp/2010-04-14-rev-agro.pdf

Machín Sosa, A., Roque, A. M.; Ávila, D. R.; Rosset, P. M. Agroecological revolution: the farmer-to-farmer movement of the ANAP in Cuba. La Habana: ANAP y La Via Campesina, 2013. Accesible en: https://viacampesina.org/ downloads/pdf/en/Agroecological-revolution-ENGLISH. pdf

Martínez-Alier, J. The environmentalism of the poor: a study of ecological conflicts and valuation. Cheltenham: Edward Elgar, 2002.

Martínez-Torres, M. E. Organic coffee: sustainable development by Mayan farmers. Athens: Ohio University Press, 2006.

Martínez-Torres, M. E.; Rosset, P. M. Diálogo de saberes in La Vía Campesina: food sovereignty and agroecology. Journal of Peasant Studies, 41(6), 979-997, 2014. doi: 10.1080/03066150.2013.872632

McCune, N.; Reardon, J.; Rosset, P. Agroecological formación in rural social movements. Radical Teacher, 98, 31-37, 2014. doi: 10.5195/RT.2014.71

McCune, N.; Rosset, P. M.; Cruz, T.; Saldívar, A.; Morales, H. Mediated territoriality: rural workers and the efforts to scale out agroecology in Nicaragua. The Journal of Peasant Studies, 44(2), 354-376, 2016. doi: 10.1080/0 3066150.2016 .1233868

McCune, N.; Rosset, P. M.; Cruz, T.; Saldívar, A.; Morales, $\mathrm{H}$. The long road: rural youth, farming and agroecological formación in Central America. Mind, Culture, and Activity, 24(3), 183-198, 2017. doi: 10.1080/10749039.2017.1293690

McLaren, P. Che Guevara, Paulo Freire y la pedagogía de la revolución. México: Siglo XXI, 2001.

McMichael, P. Food regimes and agrarian questions. Agrarian change and peasant studies. Nova Scotia, Canada: Fernwood Publishing, 2013. 
Méndez, V. E.; Bacon, C.; Cohen, R. Agroecology as a transdisciplinary, participatory, and action-oriented approach. Agroecology and Sustainable Food Systems, 37, 3-18, 2013.

Misra, S. Risks, farmers' suicides and agrarian crisis in India: Is there a way out? Indian Journal of Agricultural Economics, 63(1), 38-54, 2008.

Mohanty, B. 'We are like the living dead': farmer suicides in Maharashtra, western India. Journal of Peasant Studies, 32(2), 243-276, 2005. doi: 10.1080/03066150500094485

Montagut, X.; Gascón, J.; Riera, N. Entrevista a Peter Rosset: Una visión de las políticas agrarias en América Latina. En: Gascón, J.; Montagut, X. (Coords.). ¿Cambio de Rumbo en la Políticas Agrarias Latinoamericanas? Estado, movimientos sociales campesinos y soberanía alimentaria. Barcelona, España: Icaria, cap. 8, 2010.

Morales, H. Pest management in traditional tropical agroecosystems: Lessons for pest prevention research and extension. Integrated Pest Management Reviews, 7(3), 145163, 2002. doi: 10.1023/B:IPMR.0000027502.91079.01

Nicholls, C. I.; Parrella, M.; Altieri, M. A. The effects of a vegetational corridor on the abundance and dispersal of insect biodiversity within a northern California organic vineyard. Landscape Ecology, 16(2), 133-146, 2001.

Nigh, R. Acción colectiva, capital social y recursos naturales: Las organizaciones agroecológicas de Chiapas. En: Vargas, G. (Coord.). De lo privado a lo público. Organizaciones en Chiapas. México: CIESAS y Porrúa, cap. 2, 2002.

Oliveira, J. A.; Baccarin, J. G. Organização espacial e execução do programa de aquisição de alimentos da agricultura familiar entre 2003-2012. Revista Equador, 5(2), 120-138, 2016.

Parmentier, S. Scaling-up agroecological approaches: what, why and how? Bélgica: Oxfam-Solidarity, 2014. Accesible en: https://www.oxfamsol.be/fr/scaling- agroecologicalapproacheswhatwhy-and-how

Patel, R. Stuffed and starved: the hidden battle for the world's food system. London: Portobello Books, 2007.

Perez-Cassarino, J. A construção social de mecanismos alternativos de mercados no âmbito da Rede Ecovida de agroecologia. Curitiba, Tesis (Doctorado em Medio Ambiente y Desarollo) - UFPR, 2012. Accesible en: http:// acervodigital.ufpr.br/handle/1884/27480

Petersen, P.; Mussoi, E. M.; Soglio, F. D. Institutionalization of the agroecological approach in Brazil: advances and challenges. Agroecology and Sustainable Food Systems, 37(1), 103-114, 2013.

Perfecto, I.; Vandermeer, J.; Wright, A. Nature's matrix: linking agriculture, conservation and food sovereignty. London: Routledge, 2009.

Pretty, J. Some benefits and drawbacks of local food systems. Briefing Note for TVU/Sustain AgriFood Network, 2001. Accesible en: https://www.sustainweb.org/pdf/ afn_m1_p2.pdf Acceso en: 28/07/2016

Radomsky, G. F. W. Certificação participativa e regimes de propriedade intelectual. Porto Alegre, Tesis (Doctorado en Antopología Social) - UFRGS, 2010.

Radomsky, G. F. W.; Leal, O. F. Ecolabeling as a sustainability strategy for smallholder farming? The emergence of participatory certification systems in Brazil. Journal of Sustainable Development, 8(6), 196-207, 2015.

Ranaboldo, C.; Venegas, C. Escalonando la agroecología. Procesos y aprendizajes de cuatro experiencias en Chile, Cuba, Honduras y Perú. Canadá: Centro Internacional de Investigaciones para el Desarrollo (IDRC) y Plaza y Valdés, 2007.

Renard, M. C. Fair trade: Quality, market and conventions. Journal of Rural Studies, 19(1), 87-96, 2003. doi: 10.1016/ S0743-0167(02)00051-7

Rosset, P. M. Social organization and process in bringing agroecology to scale. En: Proceedings of the FAO International Symposium. Agroecology for food security and nutrition. Rome: FAO, 18-18 sept., 2014 Accesible en: http://www.fao.org/3/a-i4729e.pdf

Rosset, P. M.; Altieri, M. A. Agroecology versus input substitution: a fundamental contradiction of sustainable agriculture. Society and Natural Resources, 10(3), 283-295, 1997. doi: 10.1080/08941929709381027

Rosset, P. M.; Altieri, M. A. Agroecología. Ciencia y Política. Sociedad Científica Latinoamericana de 
Agroecología SOCLA, 2018. Accesible en: <http://celia. agroeco.org/wp-content/uploads/2018/12/Rosset-y-Altieritexto-completo-sin-portada-1.pdf $>$. Acceso en: jul. 2018.

Rosset, P. M.; Machín Sosa, B.; Roque, A. M.; Ávila, D. R. The Campesino-to-Campesino agroecology movement of ANAP in Cuba: social process methodology in the construction of sustainable peasant agriculture and food sovereignty. Journal of Peasant Studies, 38(1), 161-191, 2011. doi: $10.1080 / 03066150.2010 .538584$

Rosset, P. M.; Martínez-Torres, M. E. Rural social movements and agroecology: context, theory, and process. Ecology and Society, 17(3), 2012. doi: 10.5751/ES-05000170317

Rover, O. J. Agroecologia, mercado e inovação social: o caso da Rede Ecovida de Agroecologia. Ciências Sociais Unisinos, 47(1), 56-63, 2011. doi: 10.4013/csu.2011.47.1

Rover, O. J.; Corrado De Gennaro, B.; Roselli, L. Social innovation and sustainable rural development: the case of a Brazilian agroecology network. Sustainability, 9(1), 3, 2016. doi: $10.3390 /$ su9010003

Salazar, D. Nicaragua: Potencial faro regional para el diseño y evaluación de agroecosistemas agroecológicos. La Calera, 13(20), 58-65, 2014.

Scoones, I.; Thompson, J. (Eds.). Beyond farmer first: rural people's knowledge, agricultural research and extension practice. London, UK: Intermediate Technology Publications, 1994.

Siliprandi, E. Mulheres e agroecologia: transformando o campo, as florestas e as pessoas. Rio de Janeiro, Brazil: Editora UFRJ, 2015. Accesible en: http://www.mda.gov. $\mathrm{br} / \mathrm{sitemda} / \mathrm{sites} /$ sitemda/files/ceazinepdf/MULHERES_E_ AGROECOLOGIA_TRANSFORMANDO_O_CAMPO_ AS_FLORESTAS_E_AS_PESSOAS_0.pdf.

Siliprandi, E.; Zuluaga, G. P. (Eds.). Género, agroecología y soberanía alimentaria: perspectivas ecofeministas. Barcelona, España: Icaria, 2014.

Tait, M. Camponesas, feminismos e lutas atuais: resistência a potência na construção de epistemologias do Sul. Mundos Plurales. Revista Latinoamericana de Política y Acción Pública, 2(1), 77-102, 2015.
Tapia, G. Ética ecológica y derechos de las mujeres: un acercamiento a los movimientos socioambientales en México. Dilemata, 8(21), 227-252, 2016.

Touraine, A. Qu'est-ce que la démocratie? France: Fayard, 1994.

Turner, L. Del pensamiento pedagógico de Ernesto Che Guevara. La Habana: Editorial Capitán San Luis, 2007.

Vakulabharam, V. Agrarian crisis in India. The Journal of Peasant Studies, 40(1), 300-303, 2013. doi: $10.1080 / 03066150.2012 .754260$

Val, V. Sembrando alternativas; cosechando esperanzas: $(\mathrm{Re})$ campesinización agroecológica en las lomas del Escambray, Provincia de Villa Clara, Cuba. San Cristóbal de las Casas - Tesis (Maestría en Antropología Social) CIESAS, 2012.

Van Der Ploeg, J. D. The new peasantries. Struggles for autonomy and sustainability in an Era of empire and globalization. London and Sterling, VA: Earthscan, 2008.

Van Der Ploeg, J. D. The drivers of change: the role of peasants in the creation of an agro-ecological agriculture. Agroecología, 6, 47-54, 2012.

Van Der Ploeg, J. D. Peasants and the art of farming: a Chayanovian manifesto. Agrarian change and peasant studies. Series 2. Winnipeg: Fernwood, 2013.

Vandermeer, J.; Perfecto, I. The agroecosystem: a need for the conservation biologist's lens. Conservation Biology, 11, 591-592, 1997. doi: 10.1046/j.1523-1739.1997.07043.x

Vandermeer, J.; Perfecto, I. Ecological complexity and agroecology. London and Sterling, VA: Routledge, 2017.

Vásquez, J. I.; Rivas, A. De campesino a campesino. Managua: Unión Nacional de Agricultores y Ganaderos, 2006.

Vergara-Camus, L.; Kay, C. Agribusiness, peasants, leftwing governments, and the state in Latin America: an overview and theoretical reflections. Journal of Agrarian Change, 17, 239-257, 2017. doi: 10.1111/joac. v17.2

Vyas, V. S. Agrarian distress: Strategies to protect vulnerable sections. Indian Journal of Labour Economics, 48(1),1928, 2005. 
Wezel, A.; Bellon, S.; Doré, T.; Francis, C.; Vallod, D.; Wittman, H.; Blesh, J. Food sovereignty and fome zero: David, C. Agroecology as a science, a movement and a connecting public food procurement programmes to practice. A Review. Agronomy for Sustainable Development, sustainable rural development in Brazil. Journal of Agrarian 29(4), 503-515, 2009. doi: 10.1051/agro/2009004

Change, 17(1), 81-105, 2017. doi: 10.1111/joac.12131 